\title{
Improving Multiple Shoot Proliferation in Bamboo Mosaic Virus-free Bambusa oldhamii Munro Propagation by Liquid Culture
}

\author{
Choun-Sea Lin ${ }^{1}$ \\ Agricultural Biotechnology Research Center, Academia Sinica, Taipei, \\ Taiwan and China Institute of Technology, 235 Academia Boulevard sec 3, \\ Taipei, Taiwan \\ Krishnan Kalpana, Wei-Chin Chang, and Na-Sheng Lin \\ Institute of Plant and Microbial Biology, Academia Sinica, Taipei, Taiwan, \\ 115, Republic of China
}

Additional index words. in vivo flowering, micropropagation, plant growth regulators

\begin{abstract}
An in vitro method for obtaining bamboo mosaic virus (BaMV)-free plantlets of Bambusa oldhamii Munro was developed. BaMV-free meristems were incubated on MS basal medium supplemented with $0.45 \mu \mathrm{M}$ thidiazuron (TDZ) to induce the development of multiple shoots. Multiple shoot proliferation was higher in stationary liquid culture than on semisolid medium. Cytokinin was the key component for inducing proliferation, and TDZ was the stable and effective cytokinin for proliferation in long-term subcultures. Multiple shoots rooted after 1 month in MS basal medium containing 10.74 to $26.85 \mu_{M} \alpha$-naphthaleneacetic acid with a rooting efficiency of $83 \%$. Healthy, welldeveloped plantlets were transferred to soil in pots and raised in a greenhouse. Those plants derived from tissue culture were more vigorous than the ones derived from the traditional in vivo vegetative propagation method, air layering. The tissue culturederived plants could produce the culms after 15 months. Fifteen of 38 plants flowered 2 years after being transplanted to the field.
\end{abstract}

Bambusa oldhamii Munro, also known as "green timber bamboo," is a well-known semitropical clumping bamboo species native to Taiwan and southern China (Hsu et al., 2000a). Because of its large size (up to $16.5 \mathrm{~m}$ high with culms as thick as $10 \mathrm{~cm}$ ), it is grown commercially for timber and woodrelated products. In addition, its very young green shoots are edible and considered to be a culinary delicacy in Taiwan. A serious problem in the commercial cultivation of $B$. oldhamii is the prevalence of viral disease, bamboo mosaic virus (BaMV). This virus can reduce quality and cause as much as a $50 \%$ decrease in yield (Hsu et al., 2000b). In vitro virus-free systems that promote the successful regeneration of plants have contributed significantly to crop improvement by overcoming many of the limitations of in vivo

\footnotetext{
Received for publication 19 Oct. 2006. Accepted for publication $19 \mathrm{Feb} .2007$.

This work was supported by grants from the National Science Council of Taiwan.

We thank Tzu Wei, Fang-Yi Jhang, and Jiang-Tai $\mathrm{Wu}$ for maintaining the in vitro materials and virus detection. We also thank Kou-Tzan Chang for the B. oldhamii shoots and the field work.

${ }^{1}$ To whom reprint requests should be addressed; e-mail cslin99@hotmail.com
}

propagation systems. In previous studies, the researchers used seeds, seedlings, or reproductive explants to establish somatic embryogenesis (Yeh and Chang, 1986) and multiple shoots proliferation (Kapoor and Rao, 2006; Nadgauda et al., 1990; Sood et al., 2002). However, it is very difficult to obtain bamboo reproductive tissues in the field. Lin and Chang (1998) used field-grown vegetative shoot meristems to induce multiple shoots in vitro, which were subsequently used as explants to establish somatic embryogenesis in B. edulis Munro (Lin et al., 2004). This method could provide the healthy plantlets without any seasonal limitations.

Unlike B. edulis, in our preliminary investigation, the multiple shoot proliferation of $B$. oldhamii is very low when these shoots were incubated on semisolid medium. The same problem also occurred in Guadua angustifolia (Jiménez et al., 2006). We report here an efficient protocol using in vitro shoot meristem culture to establish a BaMV-free micropropagation for B. oldhamii. We also report the in vivo flowering and the production of albino mutants in $B$. oldhamii.

\section{Methods and Materials}

Plant material and medium preparation. Shoots from field-grown $B$. oldhamii were used as the source of material for in vitro culture. Total RNA was isolated from leaves, and dot-blot hybridization was carried out to detect the presence of BaMV as described by Hsu et al. (2000b). The meristems of shoots removed from BaMV-free plants were then used as explants to generate in vitro plants. Twenty nodes $(\approx 5 \mathrm{~cm}$ long each) were excised and soaked in $2 \%$ sodium hypochlorite with sonication for $30 \mathrm{~min}$. After three thorough washes in sterilized distilled water, the meristem explants were excised and cultured in 2-cm-diameter test tubes containing $10 \mathrm{~mL}$ semisolid MS basal medium (Murashige and Skoog, 1962) supplemented with $0.45 \mu \mathrm{M}$ thiadiazuron (TDZ; Sigma, St. Louis) as described by Lin and Chang (1998) under a 16/8-h (light/dark) photoperiod with artificial lighting provided by daylight fluorescent tubes (FL-30D/29, 40 W; China Electric Co., Taipei) at an intensity of $54 \mu \mathrm{mol} \cdot \mathrm{m}^{-2} \cdot \mathrm{s}^{-1}$. All tissue culture media contained MS salts (Murashige and Skoog, 1962), 3\% (w/v) sucrose, and $2.2 \mathrm{~g} \cdot \mathrm{L}^{-1}$ Gelrite. All plant growth regulators were added before the medium was adjusted to $\mathrm{pH}$ 5.7. The newly emerging multiple shoots were subcultured at 21-d intervals on the same medium.

Multiple shoot proliferation. To compare liquid culture [no shaking and shaking (orbital, $120 \mathrm{rpm}$ )] and culture on semisolid medium for their ability to induce shoot proliferation, we cultured three clusters of shoots, each having three to five multiple shoots in $125-\mathrm{mL}$ flasks, which either contained $25 \mathrm{~mL}$ semisolid medium or liquid medium supplemented with $0.45 \mu \mathrm{M}$ of the TDZ counterpart and compared multiple shoot proliferation. The cultures were grown for $21 \mathrm{~d}$ under the same conditions as described, after which healthy regenerated plantlets were selected out and used as explants for the second and third subcultures. Multiple shoot proliferation was calculated as the number of multiple shoots after a 21-d incubation period divided by the initial number of multiple shoots. Data of multiple shoot proliferation rates were collected from nine clusters of multiple shoots $(n=9)$. For longterm observation, multiple shoots in one experiment were further subcultured for $21 \mathrm{~d}$ and then transferred to fresh medium with the same concentration. Each experiment was repeated three times.

For studying the effects of TDZ and cytokinin, one cluster of shoots having three to five shoots was incubated in 125 -mL flasks with $25 \mathrm{~mL}$ liquid medium. In TDZ concentration experiments, $0,0.05,0.45,2.27$, and $4.54 \mu \mathrm{M}$ of TDZ were tested. In cytokinin experiments, $\mathrm{N}^{6}$-[2-isopenteny] adenosine (2-ip; Sigma), zeatin (Sigma), kinetin (Sigma), 6-benzylaminopurine (BA; Sigma), and TDZ were added to the basal medium and tested for their effects on multiple shoot proliferation. The cultures were grown and subcultured as described. Multiple shoot proliferation was calculated as the number of multiple shoots after a 21-d incubation period divided by the initial number of multiple shoots. For long-term observation, 
green multiple shoots in one experiment were further subcultured for $21 \mathrm{~d}$ and then transferred to fresh medium with the same concentration. Data on the multiple shoot proliferation rate were collected from three flasks $(n=3)$, and each experiment was repeated three times.

Rooting. In 2005 through 2006, to study the effect of auxins on rooting, one cluster of multiple shoots (three to five shoots) was cultured into a test tube containing $10 \mathrm{~mL}$ of MS basal medium supplemented with various components (Gelrite and auxin). In liquid experiments, 0 and $2.2 \mathrm{~g} \cdot \mathrm{L}^{-1}$ Gelrite were added into to the basal medium. In auxin experiments, $\alpha$-naphthaleneacetic acid (NAA; Sigma), indole-3-acetic acid (IAA; Sigma), indole-3-butyric acid (IBA; Sigma), picloram (Sigma), 2,4-dichlorophenoxyacetic acid (2,4-D; Sigma), and 3,6-dichloro-2-methoxybenzoic acid (dicamba; Sigma) were added to investigate the effect on rooting. The cultures were grown for 1 month under the same conditions as described. Data on rooting, root number, and root length were collected from 18 tubes $(n=18)$, and each experiment was repeated three times. Wellrooted plantlets were planted in plastic pots containing a soil mixture of peat, perlite, and vermiculite $(1: 1: 1)$ and placed under greenhouse conditions that averaged 20 to $30{ }^{\circ} \mathrm{C}$ with a high relative humidity $(90 \%$ to $100 \%$ ).

Data collection. We observed the existence of root formation and visually counted the numbers of shoot and inflorescence. The shoot proliferation ratio and rooting are defined as follows:

shoot proliferation ratio

$$
=\frac{\text { No. of shoots after incubation }}{\text { No. of original shoots }}
$$

rooting $(\%)$

$$
=\frac{\text { No. of multiple shoots with root } \times 100}{\text { No. of total multiple shoots }}
$$

Variance analysis was conducted using Costat (CoHort Software, Monterey, CA). Duncan's multiple range test was used for mean separation when significant treatment effects were present (Duncan, 1955).

\section{Results and Discussion}

Micropropagation. Multiple shoots developed from the meristems within 2 weeks of culture initiation in the semisolid culture systems containing $0.45 \mu \mathrm{M}$ TDZ. However, in subsequent subcultures on semisolid medium supplemented with $0.45 \mu \mathrm{M}$ TDZ, multiple shoot proliferation was slow (Table 1; proliferation $=1.20$ times) and the lower leaves turned yellow and exhibited wilting symptoms. We attempted to increase the proliferation and growth of multiple shoots in B. oldhamii by using liquid culture supplemented with $0.45 \mu \mathrm{M}$ TDZ and found that the multiple shoots grew well and with high rates of proliferation (Table 1,
Table 1. Effect of culture conditions on multiple shoot proliferation on MS basal medium supplemented with $0.45 \mu \mathrm{M}$ thidiazuron.

\begin{tabular}{lccc}
\hline & First subculture $(21 \mathrm{~d})$ & Second subculture $(42 \mathrm{~d})$ & Third subculture $(63 \mathrm{~d})$ \\
\hline Semisolid & $1.39 \mathrm{~b}$ & $1.21 \mathrm{~b}$ & $1.19 \mathrm{~b}$ \\
Liquid + shaking & $2.70 \mathrm{a}$ & $1.53 \mathrm{~b}$ & $1.42 \mathrm{~b}$ \\
Liquid & $2.20 \mathrm{a}$ & $2.13 \mathrm{a}$ & $1.99 \mathrm{a}$ \\
\hline
\end{tabular}

Green multiple shoot in one experiment were further subcultured for $21 \mathrm{~d}$ and then transferred to fresh medium with same concentration (first subculture, $21 \mathrm{~d}$; second subculture, $42 \mathrm{~d}$; third subculture, $63 \mathrm{~d}$ ). Means followed by the same letter are not significantly different (least significant difference test, $P<0.05$; Duncan, 1955).

Fig. 1A). With the exception of the first subculture, shaking did not increase the proliferation of multiple shoots in the long term (Table 1).

Albino mutants were also observed in the liquid medium supplemented with $0.45 \mu \mathrm{M}$ TDZ (Fig. 1B). These mutants were able to grow and proliferate in the same medium as their normal counterparts (Fig. 1C). Albino mutants also occurred in another system (Lin and Chang, 1998). Unlike the high percentage and early occurrence (second subculture) of albino mutants in B. edulis culture (Lin and Chang, 1998), there were only three mutants generated in subsequent cultures. Compared with $B$. edulis, the mechanism of the mutagenesis is also different in B. oldhamii. The albino mutants of $B$. edulis were generated because of the deletion in the chloroplast genome. In $B$. oldhamii, by using the genomic polymerase chain reaction method, there was no deletion in these mutants (data no shown). This phenomenon indicates that the mechanisms of albino generation are different in B. edulis and B. oldhamii (Liu et al., 2007).

The presence of 0.45 to $4.54 \mu \mathrm{M}$ TDZ promoted shoot proliferation in each of the 21-d subcultures (Table 2). The highest shoot proliferation occurred in $2.27 \mu \mathrm{M}$ TDZ. In subsequent experiments, multiple shoots were incubated in liquid MS basal medium supplemented with $0.45 \mu \mathrm{M}$ TDZ.

Cytokinins other than TDZ also enhanced shoot proliferation. Although the highest shoot proliferation was found in the first subculture in medium supplemented with $22.2 \mu \mathrm{M}$ BA, there was no significant difference among TDZ, zeatin, and kinetin tested (Table 3 ). The cytokinin 2-ip could not enhance shoot proliferation in the second and third subcultures (Table 3 ).
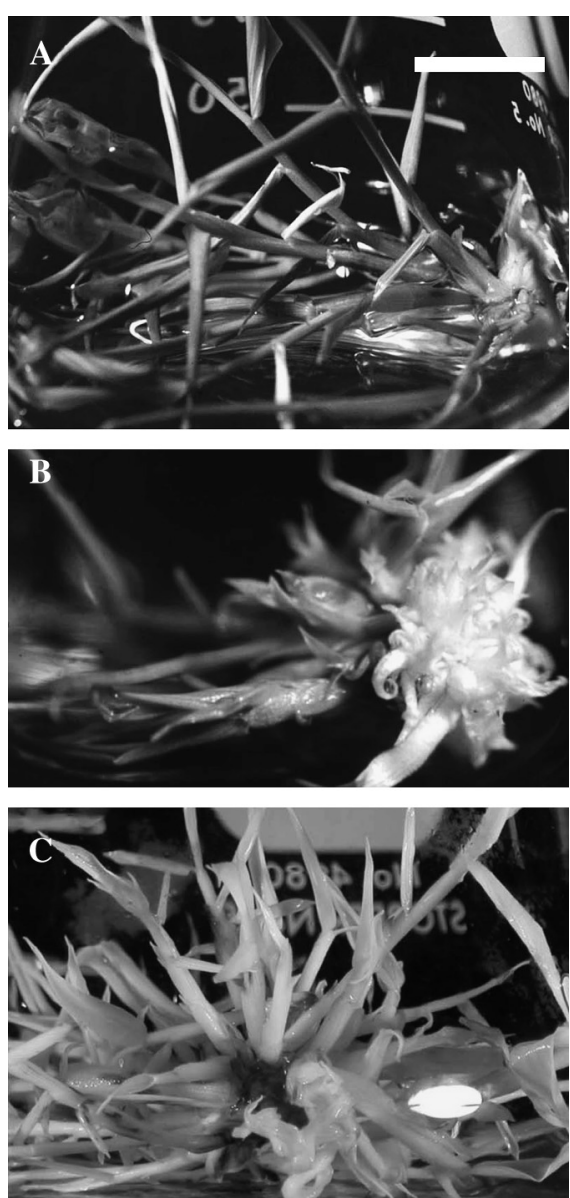

Fig. 1. Liquid culture of Bambusa oldhamii. (A) Normal shoot growth after $21 \mathrm{~d}$ of culture in liquid medium supplemented with $0.45 \mu \mathrm{M}$ thidiazuron (TDZ) (bar $=2 \mathrm{~cm})$. (B) Albino shoots regenerated in liquid medium with $0.45 \mu \mathrm{M}$ TDZ after $21 \mathrm{~d}$ (bar $=2 \mathrm{~cm})$. (C) Albino shoots proliferating in liquid medium with $0.45 \mu \mathrm{M}$ TDZ after $21 \mathrm{~d}($ bar $=2 \mathrm{~cm})$.

Table 2. Effect of thidiazuron (TDZ) concentrations on shoot proliferation.

\begin{tabular}{lccc}
\hline TDZ $(\mu \mathrm{M})$ & First subculture $(21 \mathrm{~d})$ & Second subculture $(42 \mathrm{~d})$ & Third subculture $(63 \mathrm{~d})$ \\
\hline 0 & $1.18 \mathrm{c}$ & $1.04 \mathrm{c}$ & $1.34 \mathrm{c}$ \\
0.05 & $1.68 \mathrm{c}$ & $1.54 \mathrm{c}$ & $1.55 \mathrm{c}$ \\
0.45 & $2.64 \mathrm{~b}$ & $2.63 \mathrm{~b}$ & $2.49 \mathrm{ab}$ \\
2.27 & $4.90 \mathrm{a}$ & $5.80 \mathrm{a}$ & $2.95 \mathrm{a}$ \\
4.54 & $2.71 \mathrm{~b}$ & $3.50 \mathrm{~b}$ & $1.90 \mathrm{bc}$ \\
\hline
\end{tabular}

Cultures were grown in light condition on MS basal medium containing $30 \mathrm{~g} \cdot \mathrm{L}^{-1}$ sucrose. Green multiple shoot in one experiment were further subcultured for $21 \mathrm{~d}$ and then transferred to fresh medium with same concentration (first subculture, $21 \mathrm{~d}$; second subculture, $42 \mathrm{~d}$; third subculture, $63 \mathrm{~d}$ ). Means followed by the same letter are not significantly different (least significant difference test, $P<0.05$; Duncan, 1955). 
The addition of the auxin NAA to the liquid culture medium increased the percentage of rooting. Only $22 \%$ of the multiple shoots rooted on hormone-free semisolid medium; this percentage increased to $78 \%$ after the explants were transferred to liquid medium containing $26.85 \mu \mathrm{M}$ NAA (Fig. 2A) with the roots developing from the base of the young shoots (Fig. 2B). All of the auxins tested enhanced rooting, with the exception of 2,4-D, picloram and dicamba at the higher concentration (Table 4). NAA was the most effective auxin for root induction, and there was no difference between 10.74 and 26.85 $\mu \mathrm{M}$. The auxin treatments affected the morphology and length of the roots. NAA treatment resulted in more and longer roots relative to the other auxins (Table 4). Although the lower concentration $(9.05 \mu \mathrm{M})$ of 2,4-D, picloram, and dicamba increased rooting and root number, it inhibited root length (Table 4, Fig. 2C).

The results showed that multiple shoots proliferated in the liquid MS basal medium supplemented with $0.45 \mu \mathrm{M}$ TDZ than rooting in the liquid MS medium supplemented with $26.85 \mu \mathrm{M}$ NAA. This liquid axillary shoot proliferation protocol was repeated three times. The multiple shoots were subcultured for 1,3 , or 8 years before the rooted plantlets were transferred to a greenhouse and eventually a field. There was no significant difference between the plantlets derived from 3-year and 8-year subcultures. According to these data, this protocol could be used in the commercial propagation for long-term propagation. In B. edulis, after 8 years of subculture, many somaclonal varieties were produced (Lin et al., 2005). This phenomenon is valuable for physiological investigation; however, the mutant plantlets have no commercial value. In the future, we will apply this protocol to $B$. edulis to control the somaclonal variation.

The plants derived from tissue culture were more vigorous than those derived from the traditionally vegetative propagated plants (Table 5). After 1 year of growth, the plants derived from tissue culture were taller and had more shoots than their traditionally propagated counterparts.

In vivo flowering. The original plants derived from tissue culture flowered in Jan. 2006. In 2006 and 2007, 20\% of the traditionally propagated (air layering and cutting) plants of B. oldhamii flowered in the field of southern Taiwan (A.S. Chen, personal communication). Interestingly, 15 plants derived from this protocol flowered after 2 years of growth in the field $(40 \%$ [15 in 38]). The flowers were normal in appearance and consisted of a lemma and palea containing six stamens and an ovary but no seed formation.

\section{Conclusion}

A protocol for the liquid multiple shoot proliferation of bamboo was established using

Table 3. Effect of cytokinin on shoot proliferation of Bambusa oldhamii.

\begin{tabular}{lccc}
\hline Cytokinin $(\mu \mathrm{M})$ & First subculture $(21 \mathrm{~d})$ & Second subculture $(42 \mathrm{~d})$ & Third subculture $(63 \mathrm{~d})$ \\
\hline - & $1.28 \mathrm{~b}$ & $1.11 \mathrm{c}$ & $1.11 \mathrm{c}$ \\
-ip $(24.1)$ & $1.28 \mathrm{~b}$ & $1.08 \mathrm{c}$ & $1.23 \mathrm{bc}$ \\
BA $(22.2)$ & $3.11 \mathrm{a}$ & $2.20 \mathrm{a}$ & $1.85 \mathrm{ab}$ \\
Kinetin $(23.2)$ & $2.25 \mathrm{ab}$ & $1.92 \mathrm{ab}$ & $1.78 \mathrm{ab}$ \\
TDZ $(0.45)$ & $2.24 \mathrm{ab}$ & $2.17 \mathrm{ab}$ & $2.34 \mathrm{a}$ \\
Zeatin $(22.8)$ & $1.64 \mathrm{~b}$ & $1.85 \mathrm{ab}$ & $1.44 \mathrm{bc}$ \\
\hline
\end{tabular}

Cultures were grown in light on MS basal medium containing $30 \mathrm{~g} \cdot \mathrm{L}^{-1}$ sucrose. Green multiple shoot in one experiment were further subcultured for $21 \mathrm{~d}$ and then transferred to fresh medium with same concentration (first subculture, $21 \mathrm{~d}$; second subculture, $42 \mathrm{~d}$; third subculture, $63 \mathrm{~d}$ ). Means followed by the same letter are not significantly different (least significant difference test, $P<0.05$; Duncan, 1955).

2-ip $=\mathrm{N}^{6}$-[2-isopenteny $]$ adenosine; $\mathrm{BA}=6$-benzylaminopurine; $\mathrm{TDZ}=$ thidiazuron.
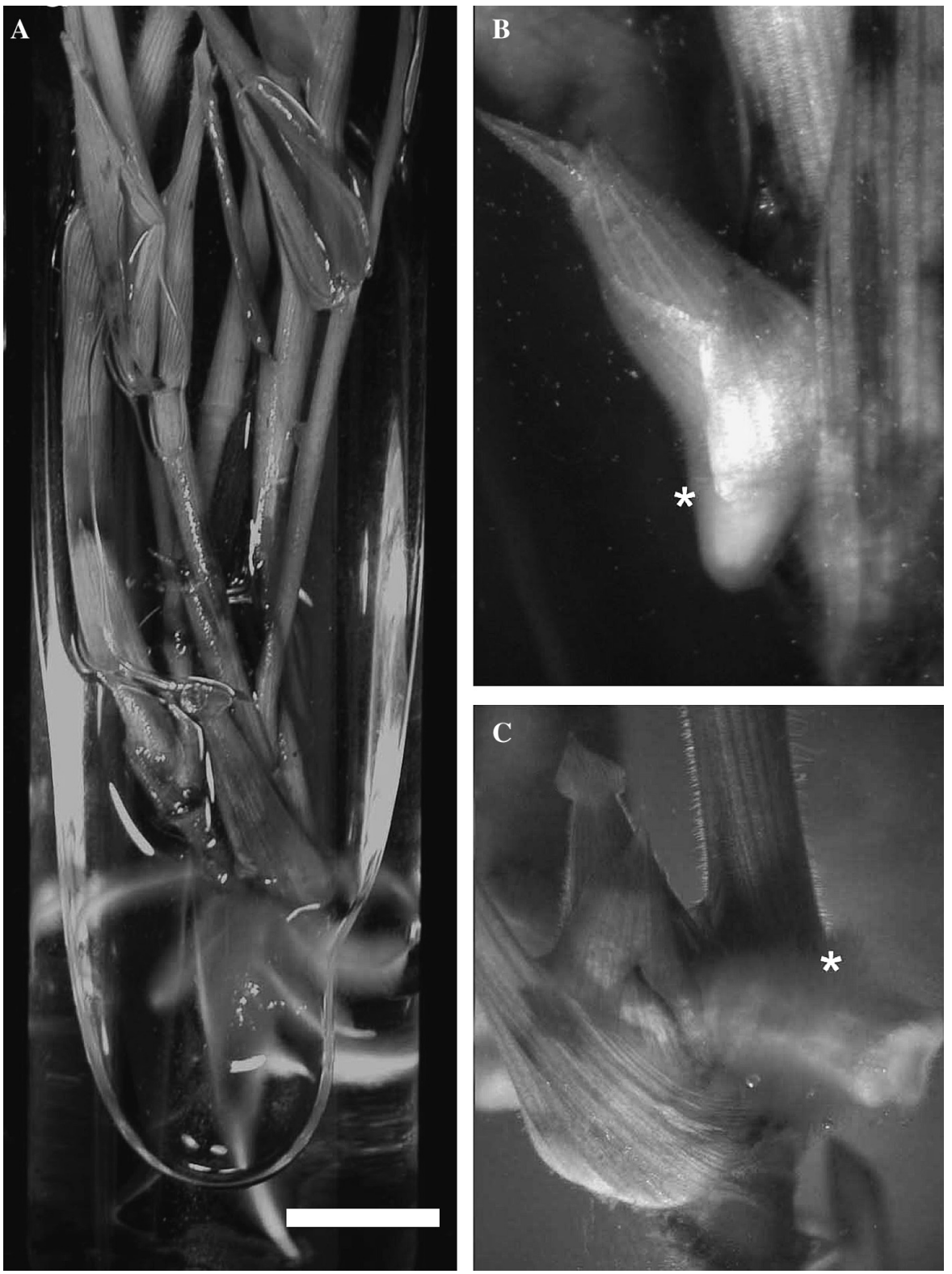

Fig. 2. Effect of auxins on the rooting of $B$. oldhamii shoots cultured in liquid medium. (A) Root formation after a 21-d culture in medium supplemented with $26.85 \mu \mathrm{M} \alpha$-naphthaleneacetic acid (NAA) (bar = $0.5 \mathrm{~cm}$ ). (B) Root formation after a 14-d culture in the medium supplemented with $28.54 \mu \mathrm{M}$ indole3-acetic acid (IAA). *Root. (C) Root formation in medium supplemented with $9.05 \mu \mathrm{M}$ 2,4,-dichlorophenoxyacetic acid (2,4-D).

TDZ and vegetative tissues from BaMV-free selected elite field-grown plants. Multiple shoot proliferation was higher in stationary liquid culture than on semisolid medium. These multiple shoots could provide the material for callus initiation. The tissue 
Table 4. Effect of different auxins on rooting.

\begin{tabular}{lcccc}
\hline Auxin $^{\mathrm{z}}$ & Concn $(\mu \mathrm{M})$ & Rooting $(\%)$ & No. of roots & Root length $(\mathrm{cm})$ \\
\hline$\overline{-}$ & & $25 \mathrm{~cd}$ & $0.35 \mathrm{bc}$ & $1.50 \mathrm{de}$ \\
NAA & 10.74 & $83 \mathrm{a}$ & $3.39 \mathrm{a}$ & $7.19 \mathrm{a}$ \\
& 26.85 & $83 \mathrm{a}$ & $4.28 \mathrm{a}$ & $7.75 \mathrm{a}$ \\
IAA & 11.42 & $61 \mathrm{ab}$ & $1.50 \mathrm{~b}$ & $3.85 \mathrm{bc}$ \\
& 28.54 & $61 \mathrm{ab}$ & $1.44 \mathrm{~b}$ & $4.69 \mathrm{~b}$ \\
IBA & 9.80 & $42 \mathrm{bc}$ & $1.31 \mathrm{~b}$ & $2.49 \mathrm{~cd}$ \\
& 24.60 & $45 \mathrm{bc}$ & $1.05 \mathrm{bc}$ & $2.18 \mathrm{cde}$ \\
Picloram & 8.28 & $52 \mathrm{abc}$ & $1.03 \mathrm{bc}$ & $0.35 \mathrm{de}$ \\
& 20.70 & $0 \mathrm{~d}$ & $0.00 \mathrm{c}$ & $0.00 \mathrm{e}$ \\
$2,4-D$ & 9.05 & $56 \mathrm{abc}$ & $1.89 \mathrm{~b}$ & $0.57 \mathrm{de}$ \\
& 22.62 & $29 \mathrm{~cd}$ & $1.18 \mathrm{~b}$ & $0.07 \mathrm{e}$ \\
Dicamba & 9.05 & $44 \mathrm{bc}$ & $1.28 \mathrm{~b}$ & $0.39 \mathrm{de}$ \\
& 22.62 & $33 \mathrm{bc}$ & $1.07 \mathrm{bc}$ & $0.11 \mathrm{e}$ \\
\hline
\end{tabular}

Means followed by the same letter are not significantly different (least significant difference test, $P<0.05$; Duncan, 1955).

${ }^{\mathrm{z}} \mathrm{NAA}=\alpha$-naphthaleneacetic acid; IAA $=$ indole-3-acetic acid; IBA $=$ indole-3-butyric acid; picloram $=$ 4-amino-3,5,6-trichloropicolinic acid; 2,4-D = 2,4-diclorophenoxyacetic acid; dicamba $=3,6$-dichloro2-methoxybenzoic acid.

Table 5. Effect of propagation methods on the growth of B. oldhamii plantlets in the field.

\begin{tabular}{lcc}
\hline & $\mathrm{Ht}(\mathrm{cm})^{\mathrm{z}}$ & $\begin{array}{c}\text { No. of } \\
\text { branches }\end{array}$ \\
\hline $\begin{array}{l}\text { Tissue culture-derived } \\
\text { Air layering }\end{array}$ & $289 \mathrm{a}$ & $5.56 \mathrm{a}$ \\
method-derived & $161 \mathrm{~b}$ & $3.78 \mathrm{~b}$ \\
\hline
\end{tabular}

${ }^{\mathrm{z}}$ Data are from the experiment with nine replicates after 1 year of growth in the field $(n=9)$. Means followed by the same letter are not significantly different (least significant difference test, $P<0.05$; Duncan, 1955).

culture-derived plantlets were more vigorous than the plantlets derived from the traditional method. tifolia Kunth, through axillary shoot proliferation. Plant Cell Tiss. Org. Cult. 86:389-395.

Kapoor, P. and I.U. Rao. 2006. In vitro rhizome induction and plantlet formation from multiple shoots in Bambusa bambos var. gigantea Bennet and Gaur by using growth regulators and sucrose. Plant Cell Tiss. Org. Cult. 85: 211-217.

Lin, C.S. and W.C. Chang. 1998. Micropropagation of Bambusa edulis through nodal explants of field-grown clums and flowering of regenerated plantlets. Plant Cell Rep. 17:617-620.

Lin, C.S., M.J. Cheng, H.W. Hsiao, P.I. Hong, F.Y. Jheng, C.C. Lin, and W.C. Chang. 2005. Stamenless inflorescence proliferation of Bambusa edulis. Sci. Hort. 107:76-80.

Lin, C.S., C.C. Lin, and W.C. Chang. 2004. Effect of thidiazuron on vegetative tissue-derived somatic embryogenesis and flowering of Bambusa edulis. Plant Cell Tiss. Org. Cult. 76:75-82.

Liu, N.T., W.N. Jane, H.S. Tsay, F.H. Wu, W.C. Chang, and C.S. Lin. 2007. Chloroplast genome aberration in micropropagation-derived albino Bambusa edulis mutants, $a b 1$ and $a b 2$. Plant Cell Tiss. Org. Cult. $88: 147-156$.

Murashige, T. and F. Skoog. 1962. A revised medium for rapid growth and bioassay with tobacco tissue culture. Physiol. Plant. 15:473-497.

Nadgauda, R.S., V.A. Parasharami, and A.F. Mascarenhas. 1990. Precocious flowering and seeding behaviour in tissue-cultured bamboos. Nature 344:335-336.

Sood, A., P.S. Ahuja, M. Sharma, O.P. Sharma, and S. Godbole. 2002. In vitro protocols and field performance of elites of an important bamboo Dendrocalamus hamiltonii Nees et Arn. Ex Munro. Plant Cell Tiss. Org. Cult. 71:55-63.

Yeh, M.L. and W.C. Chang. 1986. Plant regeneration through somatic embryogenesis in callus culture of green bamboo (Bambusa oldhamii Munro). Theor. Appl. Genet. 73:161-163. 